\title{
Attraction of the cutaneous leishmaniasis vector Nyssomyia neivai (Diptera: Psychodidae) to host odour components in a wind tunnel
}

\author{
Mara C Pinto ${ }^{1 *}$, Daniel P Bray ${ }^{2}$, Alvaro E Eiras ${ }^{3}$, Henrique P Carvalheira ${ }^{1}$ and Camila P Puertas ${ }^{1}$
}

\begin{abstract}
Background: Laboratory studies of host-seeking olfactory behaviour in sandflies have largely been restricted to the American visceral leishmaniasis vector Lutzomyia longipalpis. In comparison, almost nothing is known about the chemical ecology of related species, which transmit American cutaneous leishmaniasis (ACL), due in part to difficulties in raising these insects in the laboratory. Understanding how ACL vectors locate their hosts will be essential to developing new vector control strategies to combat this debilitating disease.

Methods: This study examined host-odour seeking behaviour of the ACL vector Nyssomyia neivai (Pinto) (=Lutzomyia neivai) using a wind tunnel olfactometer. The primary aim was to determine whether field-collected female N. neivai would respond to host odours in the laboratory, thereby eliminating the need to maintain colonies of these insects for behavioural experiments. Responses to two key host odour components, 1-octen-3-ol and lactic acid, and a commercially-available mosquito lure (BG-Lure $\left.{ }^{\mathrm{TM}}\right)$ were assessed and compared relative to an air control. We also tested whether trials could be conducted outside of the normal evening activity period of $N$. neivai without impacting on fly behaviour, and whether the same flies could be used to assess baseline responses to air without affecting responses to octenol, thereby reducing the number of flies required for experiments.

Results: Octenol was found to both activate host-seeking behaviour and attract female N. neivai in the wind tunnel, while lactic acid elicited weaker responses of activation and attractiveness under identical conditions. The BG-Lure did not activate or attract N. neivai under test conditions. Further experiments showed that sandfly behaviour in the wind tunnel was not affected by time of day, such that experiments need not be restricted to nocturnal hours. Moreover, using the same flies to measure both baseline responses to air and attraction to test compounds did not affect odour-seeking behaviour.
\end{abstract}

Conclusions: The results of this study demonstrate that $N$. neivai taken from the field are suitable for use in laboratory olfactometer experiments. It is hoped this work will facilitate further research into chemical ecology of this species, and other $\mathrm{ACL}$ vectors.

Keywords: Kairomone, Octenol, Lactic acid, Ammonia, Caproic acid, BG-Lure, Sandflies, Vector control, Wind tunnel

\footnotetext{
* Correspondence: marap@fffar.unesp.br

'Laboratório de Parasitologia, Departamento de Ciências Biológicas,

Faculdade de Ciências Farmacêuticas, Universidade Estadual Julio de

Mesquita Filho, 14801-902 Araraquara-SP, Brazil

Full list of author information is available at the end of the article
} 


\section{Background}

Despite advances in our understanding of the chemical ecology of many important disease-transmitting hematophagic insects, and particularly mosquitoes [1], very little is known about the chemicals responsible for attracting sandfly vectors of leishmaniasis to their vertebrate hosts. Most studies of chemical ecology in sandflies have focussed on the American visceral leishmaniasis vector Lutzomyia longipalpis (Lutz \& Neiva), in which attraction to both host odour components and male-produced pheromones have been demonstrated through laboratory olfactometer studies [2-5]. This initial work has led to field testing of synthetic L. longipalpis sex pheromone as a potential tool for sandfly control [6].

Of the twenty species of sandfly known or suspected to be vectors of American cutaneous leishmaniasis (ACL) [7], studies of chemical ecology have been limited to preliminary chemical analyses of potential maleproduced pheromones (without evidence of behavioural attraction [8]) and field-testing of known host odour components: $\mathrm{CO} 2$, octenol, lactic acid, ammonia and caproic acid [9-11]. This lack of knowledge is due in part to the relative difficulty in raising these species in the laboratory compared to L. longipalpis [12], which prevents researchers from conducting olfactometer studies to test for behavioural responses to potentially-attractive compounds under controlled conditions. Such studies are necessary to identify chemicals which could be exploited as tools for vector control.

The aim of the present study was to determine whether it is feasible to conduct laboratory wind tunnel studies using Nyssomyia neivai (Pinto) (=Lutzomyia neivai), considered to be a vector of ACL in South America [13-15], collected directly from the field. Using fieldcollected insects would eliminate the need for colonizing this species prior to laboratory testing, thereby providing a means of facilitating further research into the chemical ecology of ACL vectors.

A wind tunnel was used to measure and compare responses of $N$. neivai to octenol (previously shown to attract this species in the field [11]), lactic acid, and a commercially-available mosquito lure. We also tested whether test results were affected by time of day, as in the field L. neivai is most active at night [16], and if the same insects could be used to measure both baseline responses to air and activation/attraction to test stimuli, thereby reducing the number of insects required for each experiment.

\section{Methods}

Field collection and laboratory maintenance of insects Insects were collected during September and October $\left(21^{\circ} 35^{\prime} 13^{\prime} \mathrm{S} 48^{\circ} 04^{\prime} 15^{\prime} \mathrm{W}\right.$ - 12 hours natural light per day) using automatic light traps and manual aspiration from a previously studied area where $99.9 \%$ of sandflies were identified as $N$. neivai [11]. Following arrival at the laboratory, sandflies were maintained in netting cages at $26 \pm 1^{\circ} \mathrm{C}$, 80-90\% humidity, 12:12 (L:D) photoperiod with access to $30 \%$ sucrose solution. The laboratory where sand flies were kept and the wind tunnel experiments were carried out have fluorescent lights, and no access to natural light sources (e.g. windows). The fluorescent lights are controlled by a timer that switched on at 07:00 and switched off at 19:00.

All tests started on the day after sandfly capture and were conducted within three consecutive days. Following experiments, insects in both test and control groups were killed in $70 \%$ ethanol and stored for identification, following the classification of Galati $[17,18]$ and the nomenclature of Young and Duncan [19], and female abdomens inspected for the presence/absence of a bloodmeal and eggs.

\section{Wind tunnel apparatus}

All bioassays were conducted in a transparent acrylic wind tunnel (length $200 \mathrm{~cm}$, width $20 \mathrm{~cm}$, height $20 \mathrm{~cm}$; Figure 1). Air flow was obtained from a zero grade air cylinder, humidified using a water bath $\left(36^{\circ} \mathrm{C}\right)$ prior to entry through the end of the tunnel where odour sources would be presented. Air flow was set at $500 \mathrm{ml} \mathrm{min}^{-1}$ using a rotameter. Conditions within the wind tunnel were recorded as $24 \pm 1^{\circ} \mathrm{C}$ and $70-75 \%$ relative humidity. In order to maintain a constant flow of air in the tunnel, and prevent the build-up of test compounds within the apparatus, air was allowed to exit the tunnel at the opposite end to entry through an exhaust (Figure 1).

\section{Bioassay protocol}

Groups of three female $N$. neivai were placed inside a releasing chamber (Figure 1) for $30 \mathrm{~min}$ to acclimatize prior to each test. The chamber was then placed inside the wind tunnel $50 \mathrm{~cm}$ downwind from the air intake and odour source, and the sandflies released by opening the chamber door. Each trial lasted $2 \mathrm{~min}$, with activation (number of sandflies leaving the releasing chamber) and attraction (number of sandflies reaching the odour source) recorded for each group.

As a negative control, baseline responses to air flow alone were always ascertained prior to the introduction of each test chemical. The host odour component 1-octen-3-ol (98.0\% pure by gas chromatography; Aldrich Chemical, Milwaukee, WI, hereafter referred to as octenol), previously shown to attract $N$. neivai in the field [11], was used as a positive control, and to measure sandfly responses under different conditions. Except where stated, different individual sandflies were used for measuring responses to test and control stimuli. All 


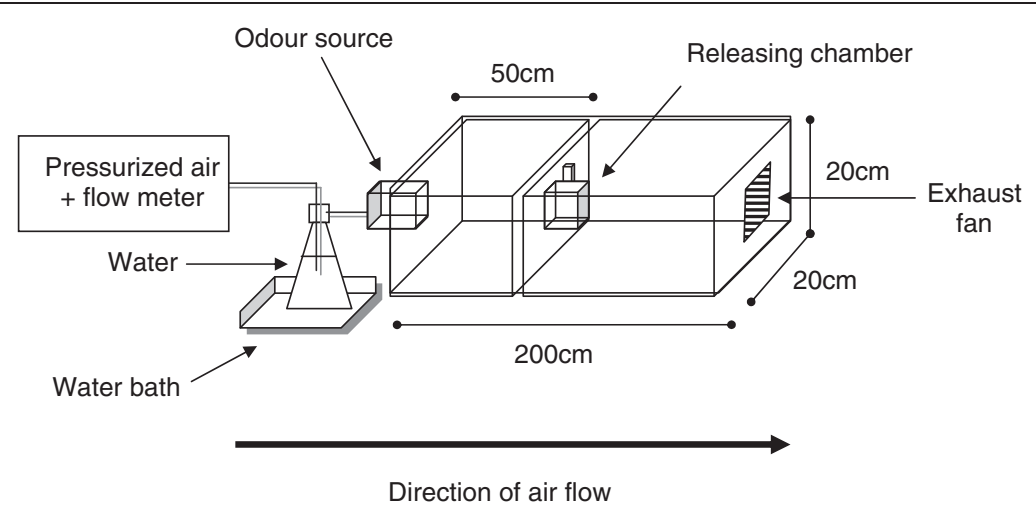

Figure 1 Wind tunnel olfactometer. Wind tunnel apparatus used to assess responses of female N. neivai to host odour components. Humidified compressed air flowed through the wind tunnel from left to right. Sandflies which left the releasing chamber were recorded as having been activated by the odour source. Sandflies which travelled to the end of the wind tunnel were recorded as having been attracted by the odour source.

experiments were conducted under white fluorescent light.

\section{Experiment 1. Can field-caught $N$. neivai be used to measure olfactory responses in the wind tunnel?}

The first experiment was conducted to determine the viability of using insects taken directly from the field in bioassays, by measuring their responses to a known attractive host odour component. The test chemical, octenol, was released from micro-reaction vials following the methodology of Van Essen et al. [20]: $1 \mathrm{ml}$ was placed into each $5 \mathrm{ml}$ tube, with two pieces of string in contact with the octenol passing through the tube lid via two small holes, leaving $4 \mathrm{~cm}$ of each length exposed outside the tube. Test vials were then placed into the wind tunnel at the air intake. Octenol release rate was determined by weighing tubes before and after experiments.

Prior to presentation of octenol, a control group of insects $(\mathrm{N}=50)$ were exposed to air flow only to ascertain baseline activation and attraction responses in the wind tunnel. Responses to octenol at $28 \mathrm{mg} \mathrm{h}^{-1}$ were then measured using a separate group of insects $(\mathrm{N}=50)$.

\section{Experiment 2. Can the same insects be used to measure responses to control and test stimuli?}

The aim of this experiment was to determine whether the same group of $N$. neivai could be used to measure baseline responses to the air control without influencing activation/attraction to the test stimuli, thereby reducing the total number of wild-caught flies needed for wind tunnel experiments.

Responses of two groups of flies to octenol $\left(32 \mathrm{mg} \mathrm{h}^{-1}\right)$ were compared: those with no prior test experience $(\mathrm{N}=50)$, and those which had previously been exposed to the control stimuli (air) $(\mathrm{N}=40)$ approximately $2 \mathrm{~h}$ beforehand.
Experiment 3. Does time of day influence $N$. neivai responses in the wind tunnel?

To determine whether the sandflies response to host odour could be measured in the wind tunnel outside of their normal nocturnal activity peak, responses of female $N$. neivai to octenol were measured and compared in experiments conducted between 09:00-12:00 and 15:0018:00 and 19:00-22:00. Octenol was released by placing $200 \mu \mathrm{l}$ onto filter paper $(4 \times 4 \mathrm{~cm})$ in the entrance of the wind tunnel.

For each time period, baseline responses to air $(\mathrm{N}=30)$ and then octenol $(\mathrm{N}=30)$ were measured using the same group of flies.

\section{Experiment 4. Is $N$. neivai attracted to lactic acid in the wind tunnel?}

This test measured sandfly responses to lactic acid, also an important host odour component, in comparison to octenol under identical laboratory conditions. Responses to L-lactic acid (85\% P.A., Synth), octenol, and the air control were measured using three separate groups of flies $(\mathrm{N}=30)$. Lactic acid and octenol were released by placing $100 \mu \mathrm{l}$ of the required test chemical onto filter paper $(4 \times 4 \mathrm{~cm})$ in the entrance of the wind tunnel.

\section{Experiment 5. Is N. neivai attracted to the BG-lure?}

The BG-Lure ${ }^{\mathrm{mm}}$ (Biogents AG, Regensburg, Germany) is a commercially available lure used for the capture of Aedes aegypti through release of a mixture of human odour components: lactic acid, ammonia and caproic acid [21]. This experiment tested whether this same lure could activate and attract female $N$. neivai in the wind tunnel, and ascertain its relative attractiveness compared to octenol and the air control.

Activation and attraction behaviours of flies $(\mathrm{N}=65)$ were measured in response to either a BG-Lure placed 
at the end of the wind tunnel, octenol released from a micro-reaction vial at $15 \mathrm{mg} \mathrm{h}^{-1}(\mathrm{~N}=50)$ and the air control $(\mathrm{N}=50)$. Different flies were used for each test.

\section{Statistical analysis}

Pearson's chi-square tests were used to test for a difference in number of flies activated and attracted by different test stimuli and the air control. Fisher's exact test was used instead where expected values in the contingency table were less than five [22], as indicated in the text.

The same methodology was used to test whether prior exposure to the air control influenced number of flies responding to octenol and air, and to compare responses at different times of the day.

Where negative results are reported (i.e. no statistical difference found), post-hoc power analysis was performed to determine the power of the experiment to detect a medium-sized effect of 0.3 [23] with the sample sizes used. All analyses were performed using R [24,25].

The responses of sandflies to octenol were compared between experiments in a post-hoc analysis, investigating the possibility of an effect of odour-release method on $N$. neivai behaviour in the wind tunnel. Chi square tests were used to test whether there was a significant difference in the proportion of sandflies both activated and attracted by the three release-methods used (micro-reaction vial loaded with $1 \mathrm{ml}$ octenol, filter paper loaded with $100 \mu \mathrm{l}$ octenol, filter paper loaded with $200 \mu$ loctenol).

\section{Results}

\section{Collected sandflies}

All 495 field-collected sandflies were identified as N. neivai. Only six females were found to contain blood meals, with four gravid with eggs. These flies did not appear to show any consistently different responses from non-gravid or non-bloodfed flies in the wind tunnel.

\section{Experiment 1}

Significantly more female $N$. neivai were activated by the presence of octenol in the wind tunnel than the air control (air 2/50, octenol 34/50, $\mathrm{X}^{2}=41.7, \mathrm{df}=1, \mathrm{P}<0.001$ ). Similarly, octenol attracted more females to the end of the wind tunnel than air flow alone (air 1/50, octenol 25/50, $\left.\mathrm{X}^{2}=27.5, \mathrm{df}=1, \mathrm{P}<0.001\right)$. This demonstrates both that octenol is attractive to female $N$. neivai in the wind tunnel, and that flies taken directly from the field can be used in laboratory olfactometer experiments.

\section{Experiment 2}

There was no significant effect of prior exposure to the control stimulus on number of sandflies activated by octenol (no prior exposure 38/50, prior exposure 29/40, $\mathrm{X}^{2}=0.02, \mathrm{df}=1$, NS, power $\left.=0.81\right)$. Similarly, there was no effect of prior exposure to air on numbers attracted to octenol (no prior exposure 26/50, prior exposure 22/40, $X^{2}=0.005, \mathrm{df}=1$, NS, power $=0.81$ ).

As in Experiment 1, in total a greater proportion of flies were both activated by octenol than the air-only control (octenol 67/90, air 2/50, $\mathrm{X}^{2}=61.0, \mathrm{df}=1, \mathrm{P}<0.001$ ), and attracted to octenol compared to the air control (octenol 48/90, air 1/50, $\mathrm{X}^{2}=35.0, \mathrm{df}=1, \mathrm{P}<0.001$ ).

\section{Experiment 3}

Baseline proportions of $N$. neivai activated and attracted by air were not affected by the time of day at which experiments took place (activation: $\mathrm{X}^{2}=0, \mathrm{df}=2, \mathrm{NS}$; attraction: $\mathrm{df}=2$, NS (Fisher's exact test (approximation for $2 \times 3$ table); power $=0.72$; Figure 2).

Similarly, responses to octenol also did not differ significantly according to time of day at which the experiments were performed (activation: $\mathrm{X}^{2}=2.0, \mathrm{df}=2, \mathrm{NS}$; attraction: $\mathrm{X}^{2}=0.53, \mathrm{df}=2, \mathrm{NS}$, power $=0.72$; Figure 2).

Octenol activated a greater proportion of sandflies than air in the morning (octenol 30/30, air 5/30, $X^{2}=39.5$, $\mathrm{df}=1, \mathrm{P}<0.001$ ), afternoon (octenol 29/30, air 5/30, $\mathrm{X}^{2}=35.9, \mathrm{df}=1, \mathrm{P}<0.001$ ) and evening (octenol 30/30, air $5 / 30, X^{2}=39.5, d f=1, P<0.001$; Figure 2). Similarly, octenol attracted more sandflies than air in the morning (octenol 23/30, air $1 / 30, \mathrm{X}^{2}=30.6, \mathrm{df}=1, \mathrm{P}<0.001$ ), afternoon (octenol 23/30, air 2/30, $\mathrm{X}^{2}=27.4, \mathrm{df}=1$, $\mathrm{P}<0.001$ ) and evening (octenol 25/30, air $2 / 30, X^{2}=32.6$ $\mathrm{df}=1, \mathrm{P}<0.001$; Figure 2), confirming that time of day had no detectable effect on $N$. neivai responses in the wind tunnel.

\section{Experiment 4}

A higher proportion of females were activated by lactic acid in the wind tunnel compared to the air control (lactic acid 9/30, air 2/30, $\mathrm{X}^{2}=4.01, \mathrm{df}=1, \mathrm{P}<0.05$; Figure 3). Lactic acid also elicited an attractive response, which bordered on significance (lactic acid 5/30, air 0/30, $\mathrm{df}=1, \mathrm{P}=0.052$ ) (Fisher's exact test). However, responses to lactic acid were relatively weak compared to octenol, which both activated $\left(27 / 30, \mathrm{X}^{2}=20.1, \mathrm{df}=1, \mathrm{P}<0.001\right.$; Figure 3$)$ and attracted $\left(19 / 30, X^{2}=11.7, d f=1, P<\right.$ 0.001 ; Figure 3 ) a higher proportion of $N$. neivai.

\section{Experiment 5}

The BG-Lure did not elicit significantly greater responses from $N$. neivai than the air control (activation, BG-Lure $3 / 65$, air $2 / 50, \mathrm{df}=1$, NS (Fisher's exact test); attraction, BG-Lure 2/65, air $1 / 65$, df $=1$, NS (Fisher's exact test); power $=0.89$; Figure 4$)$. In the same experiment, octenol activated $\left(27 / 50, \mathrm{X}^{2}=33.2, \mathrm{df}=1, \mathrm{P}<0.001\right.$; Figure 4) and attracted $\left(13 / 50, \mathrm{X}^{2}=11.1, \mathrm{df}=1, \mathrm{P}<0.001\right.$, Figure 4) a significantly greater proportion of sandflies then the BG-Lure. 

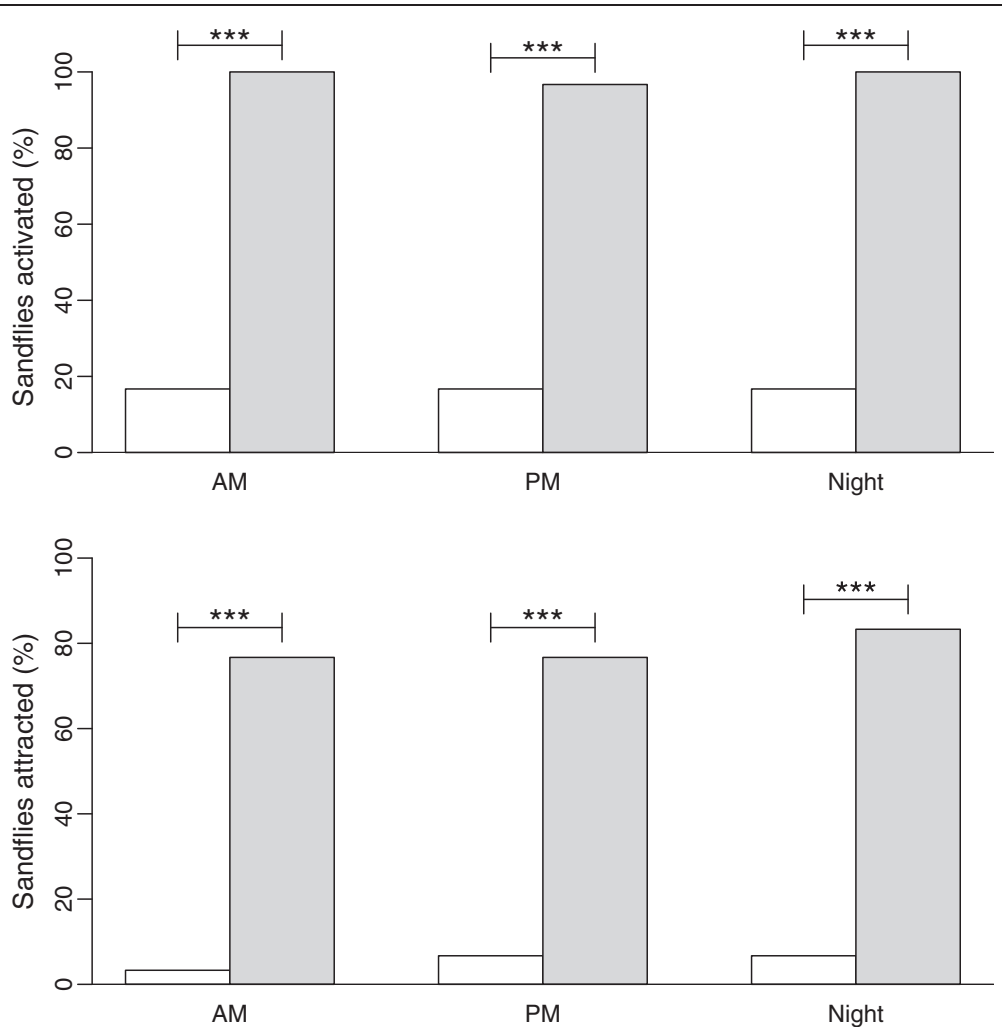

Figure $2 \mathrm{~N}$. neivai responses to air and octenol at different times of the day. Percentage of female $N$. neivai ( $N=30)$ activated (top graph) and attracted (lower graph) by air (white bars), and octenol (grey bars) in the wind tunnel (Experiment 3). ${ }^{*} \mathrm{P}<0.05,{ }^{* *} \mathrm{P}<0.01,{ }^{* * *} \mathrm{P}<0.001$.

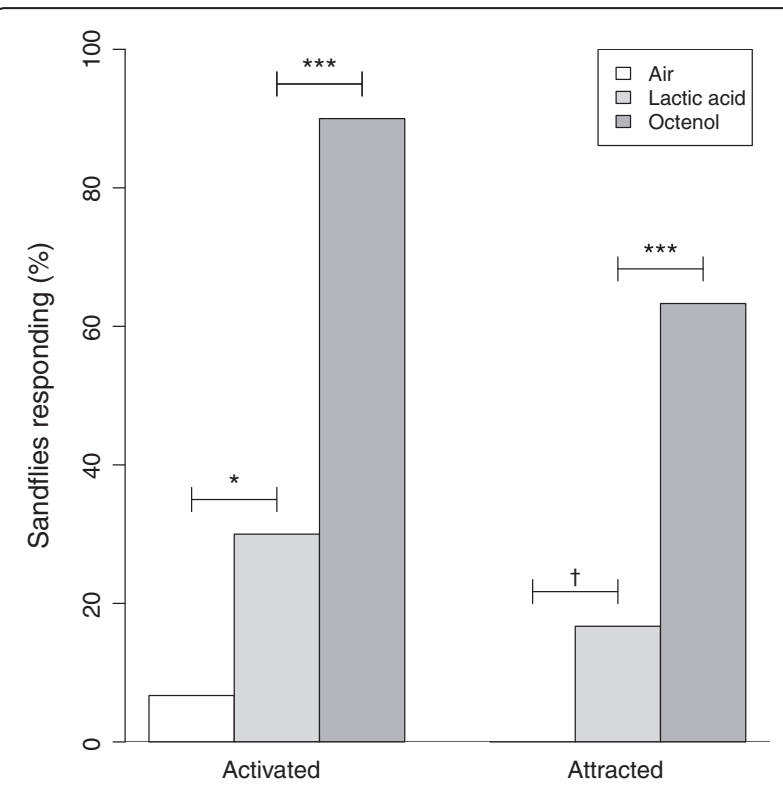

Figure $3 N$. neivai responses to air, lactic acid and octenol.

Percentage of female $N$. neivai activated and attracted by air $(\mathrm{N}=30)$, lactic acid $(\mathrm{N}=30)$ and octenol $(\mathrm{N}=30)$ in the wind tunnel

(Experiment 4). ${ }^{*} P<0.05$, ${ }^{*} P<0.01$, ${ }^{* *} P<0.001,+P=0.052$.

\section{Sandfly responses to octenol under different conditions}

In a post-hoc analysis of sandfly responses between experiments, a significant overall difference was found between tests using different methods of octenol release in terms of both the number of sandflies activated $\left(X^{2}=19.6\right.$, $\mathrm{df}=2, \mathrm{P}<0.001)$ and attracted $\left(\mathrm{X}^{2}=13.9, \mathrm{df}=2, \mathrm{P}<0.001\right.$; Table 1).

In subsequent analyses, no difference was found between experiments using filter paper loaded with $200 \mu \mathrm{l}$ or $100 \mu \mathrm{l}$ of octenol in the number of sandflies activated $(\mathrm{df}=1$, NS (Fisher's exact test) or attracted $\left.\left(\mathrm{X}^{2}=0.71, \mathrm{df}=1, \mathrm{NS}\right)\right)$. However, more $N$. neivai were both activated $\left(\mathrm{X}^{2}=17.4, \mathrm{df}=1, \mathrm{P}<0.001\right)$ and attracted $\left(\mathrm{X}^{2}=11.7, \mathrm{df}=1, \mathrm{P}<0.001\right)$ overall in experiments using filter paper as a release method than those employing micro-reaction vials.

\section{Discussion}

Experiments using blood-feeding insects reared under identical laboratory conditions can control for factors such as physiological status, which might influence hostseeking behaviour [26]. However, for N. neivai, as for many other species of sandfly, laboratory rearing is difficult to maintain over more than a few generations [27], 


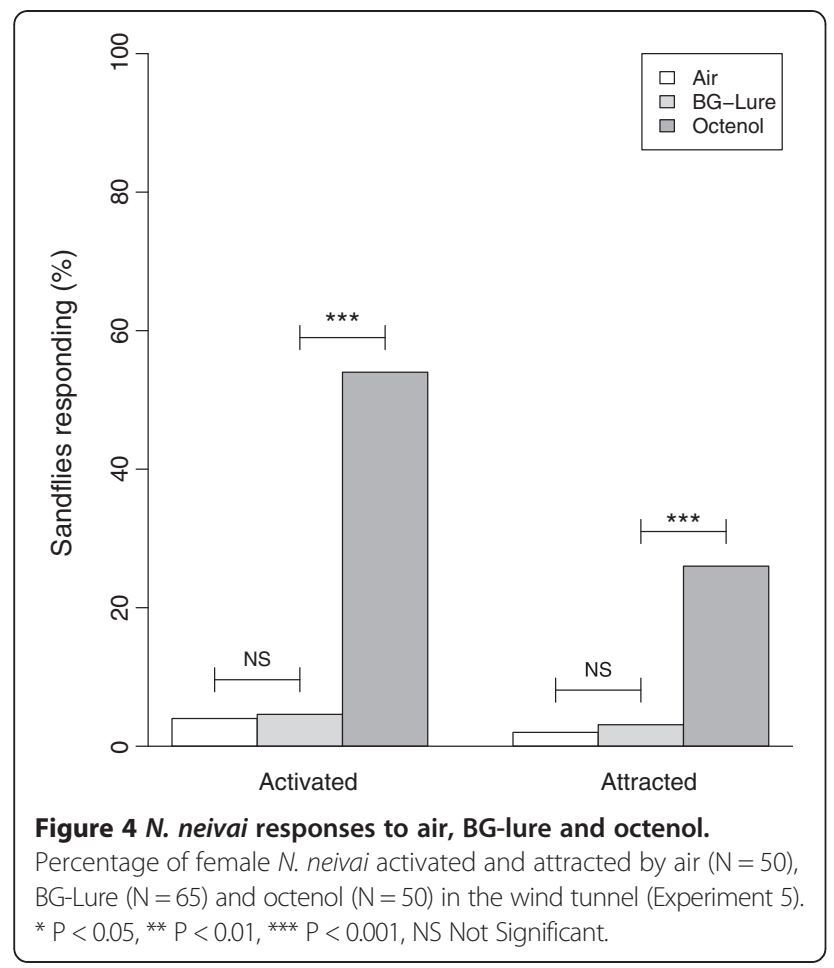

with the small number of insects produced being a limiting factor in conducting behavioural studies.

The results of this study demonstrate that, even though sandflies were taken from the field, and were of unknown age and nutritional status, female $N$. neivai showed consistently higher activation and attraction responses to 1-octen-3-ol in laboratory bioassays than an air control. In nature, octenol is released from a diverse range of sources, including fungi [28] and vertebrate breath $[29,30]$. This semiochemical, previously identified as attractive to $N$. neivai in field studies [11], also proved to be an excellent positive control for wind tunnel experiments which seek to assess responses to other potential sandfly attractants.

Often, the number of sandflies captured from the field is not sufficient to conduct all the necessary experiments in planned behavioural studies. The results of the current work showed that groups of $N$. neivai used to assess baseline responses to air flow in the wind tunnel can be reused without influencing the number of flies responding to octenol, as compared to a separate group of flies with no test experience. More studies are required to determine whether the same might be generally applicable following exposure to other semiochemicals, or if any form of learning or habituation occurs in $N$. neivai, as reported for mosquitoes [31] and other species of sandfly [32,33].

The time at which experiments are conducted is another potential source of variation in sandfly responses in laboratory bioassays: most insects follow daily cycles in activity, in part governed by endogenous circadian rhythms [34]. In nature, $N$. neivai is typically most active during nocturnal hours [16], but no previous study has examined how time of day might affect $N$. neivai responses to kairomones under laboratory conditions. Bioassays with $L$. longipalpis have been successfully performed at different times of the day (e.g. the start of the scotophase [5] and 0900-1300 [35]). The results here showed no difference in $N$. neivai responses to octenol during different parts of the day, suggesting that laboratory experiments with field collected insects need not be restricted to night and evening. However, similar experiments with other compounds should be performed to determine the general applicability of this observation. We should also make clear that all of the bioassays conducted for experiment 3 were carried out during the same $24 \mathrm{~h}$ period, with the lights on even during the night session (19:00-22:00), such that the insects had no exposure to a scotophase before the bioassay. It seems therefore that under the described conditions there was no effect of any underlying circadian rhythm on $N$. neivai host odour-seeking behaviour: previous work in L. longipalpis suggests that such rhythms in locomotory behaviour do occur in sandflies, and may be modulated by blood intake [36].

Lactic acid elicited activation responses in the wind tunnel, but was only weakly attractive: octenol both activated a greater number of $N$. neivai, and was significantly more attractive. A component of human breath [37], attraction to lactic acid has been well studied in

Table 1 Proportion of female $N$. neivai activated and attracted in the wind tunnel in response to different methods of octenol release

\begin{tabular}{|c|c|c|c|c|}
\hline \multirow[t]{2}{*}{ Experiment } & \multirow[t]{2}{*}{ Release method } & \multirow{2}{*}{$\begin{array}{l}\text { Octenol loaded } \\
\text { (released) }\end{array}$} & \multirow{2}{*}{$\frac{\text { Proportion }}{\text { Activated (\%) }}$} & \multirow{2}{*}{$\frac{\text { Proportion }}{\text { Attracted (\%) }}$} \\
\hline & & & & \\
\hline 1 & Micro-reaction vial & $1 \mathrm{ml}\left(28 \mathrm{mg} \mathrm{h}^{-1}\right)$ & $34 / 50(68)^{a}$ & $25 / 50(50)^{a}$ \\
\hline 2 & Micro-reaction vial & $1 \mathrm{ml}\left(32 \mathrm{mg} \mathrm{h}^{-1}\right)$ & $38 / 50(76)^{a}$ & $26 / 50(52)^{a}$ \\
\hline 3 & Filter paper & $200 \mu l$ & $30 / 30(100)^{b}$ & $23 / 30(83)^{b}$ \\
\hline 4 & Filter paper & $100 \mu \mathrm{l}$ & $27 / 30(90)^{b}$ & $19 / 30(63)^{b}$ \\
\hline 5 & Micro-reaction vial & $1 \mathrm{ml}\left(15 \mathrm{mg} \mathrm{h}^{-1}\right)$ & $27 / 50(54)^{a}$ & $13 / 50(26)^{a}$ \\
\hline
\end{tabular}

${ }^{\mathrm{a} b}$ Different letters within a column indicate significant differences in response towards micro-reaction vials and filter paper. 
mosquitoes, and in general is more attractive when presented synergistically in combination with other host odour components, such as $\mathrm{CO} 2$, carboxylic acid, ammonia or acetone [38-42]. In sandflies, attraction to lactic acid has only previously been assessed in the field, and was not found to be attractive to L. longipalpis or $N$. intermedia [9]. More studies are needed to assess sandfly attraction to lactic acid when presented with other host odour components, including octenol.

The BG-Lure, which releases a mixture of lactic acid, ammonia and caproic acid, was not attractive to $N$. neivai. This lure was developed to mimic human odour and has been shown to attract $A$. aegypti [21]. Interestingly, while lactic acid alone did attract a small number of sandflies, there was no response whatsoever to the BG-Lure. Potentially, this might be because either the amount of lactic acid released is too small to evoke even a minimal response, or that the other chemicals released by the lure have some masking or repellent effect.

This study made use of two different methods of releasing test chemicals within the wind tunnel. Experiments 1, 2 and 5 were performed using micro-reaction vials, following the same methodology that has been previously used in the field [10]. While octenol released from these vials did activate and attract sandflies in the wind tunnel, measurements of the weight of these vials before and after experiments suggest considerable variation may exist in their individual release rates, even when two vials are prepared and set to release under identical conditions. One potential source of this variation could be the amount of string in contact with the octenol in each vial.

Experiments 3 and 4 (performed at a later date) made use of filter paper as a release substrate. The volume of octenol was not reapplied onto filter paper during the bioassays because the responses of the sandflies did not change along the test period. Results of post-hoc analysis comparing between experiments suggest that a greater proportion of $N$. neivai were both activated and attracted by octenol released from the filter paper than from the vials, perhaps indicating a faster release rate from filter paper, and hence a greater response. However, this hypothesis requires stricter testing in order to draw firm conclusions.

\section{Conclusions}

The results of this study demonstrate that it is possible to use wild-caught $N$. neivai in wind tunnel experiments to assess responses to host odour, and highlight the greater attractiveness of octenol than lactic acid under controlled conditions. It is hoped that these results will facilitate further studies into host-seeking behaviour of both $N$. neivai and other vectors of cutaneous leishmaniasis, with the aim of developing new tools to control this debilitating, neglected disease.
Competing interests

The authors declare that they have no competing interests.

\section{Authors' contributions}

MP conceived and executed the study and drafted the manuscript. DB provided additional statistical analysis and figures and contributed to the manuscript. AE provided the BG-Lure and contributed to the manuscript. $\mathrm{HC}$ and $\mathrm{CP}$ conducted field captures of sandflies and bioassay experiments. All authors read and approved the final manuscript.

\section{Acknowledgements}

MP received a grant (F-4587-1) from the International Foundation for Science (IFS) to build the wind tunnel. DB is supported by the Wellcome Trust.

\section{Author details}

${ }^{1}$ Laboratório de Parasitologia, Departamento de Ciências Biológicas, Faculdade de Ciências Farmacêuticas, Universidade Estadual Julio de Mesquita Filho, 14801-902 Araraquara-SP, Brazil. ${ }^{2}$ Chemical Ecology Group, Institute for Science and Technology in Medicine, Keele University, ST5 5BG Keele, UK. ${ }^{3}$ Laboratório de Ecologia Química de Insetos Vetores, Departamento de Parasitologia, Instituto de Ciências Biológicas 31270-901 Universidade Federal de Minas Gerais, Minas Gerais, Brazil.

Received: 26 July 2012 Accepted: 18 September 2012 Published: 25 September 2012

\section{References}

1. Gibson G, Torr SJ: Visual and olfactory responses of haematophagous Diptera to host stimuli. Med Vet Entomol 1999, 13:2-23.

2. Morton IE, Ward RD: Laboratory response of female Lutzomyia longipalpis sandflies to a host and male pheromone source over distance. Med Vet Entomol 1989, 3:219-223.

3. Dougherty MJ, Guerin PM, Ward RD, Hamilton JGC: Behavioural and electrophysiological responses of the phlebotomine sandfly Lutzomyia longipalpis (Diptera: Psychodidae) when exposed to canid host odour kairomones. Physiol Entomol 1999, 24:251-262.

4. Ward RD: Mate recognition in a sandfly (Diptera: Psychodidae). J R Army Med Corps 1986, 132:132-134.

5. Spiegel CN, Jeanbourquin P, Guerin PM, Hooper AM, Claude S, Tabacchi R, Sano S, Mori K: (1S,3S,7R)-3-methyl-alpha-himachalene from the male sandfly Lutzomyia longipalpis (Diptera: Psychodidae) induces neurophysiological responses and attracts both males and females. J Insect Physiol 2005, 51:1366-1375.

6. Bray DP, Alves GB, Dorval ME, Brazil RP, Hamilton JG: Synthetic sex pheromone attracts the leishmaniasis vector Lutzomyia longipalpis to experimental chicken sheds treated with insecticide. Parasit Vectors 2010, 11:3-16.

7. Rangel EF, Lainson R: Proven and putative vectors of American cutaneous leishmaniasis in Brazil: aspects of their biology and vectorial competence. Mem Inst Oswaldo Cruz 2009, 104:937-954.

8. Hamilton JGC, Brazil RP, Campbell-Lendrum D, Davies CR, Kelly DW, Pessoa $\mathrm{FaC}$, de Queiroz RG: Distribution of putative male sex pheromones among Lutzomyia sandflies (Diptera: Psychodidae). Ann Trop Med Parasitol 2002, 96:83-92.

9. Andrade AJ, Andrade MR, Dias ES, Pinto MC, Eiras AE: Are light traps baited with kairomones effective in the capture of Lutzomyia longipalpis and Lutzomyia intermedia? An evaluation of synthetic human odor as an attractant for phlebotomine sand flies (Diptera: Psychodidae: Phlebotominae). Mem Inst Oswaldo Cruz 2008, 103:337-343.

10. Pinto MC, Campbell-Lendrum DH, Lozovei AL, Teodoro U, Davies CR Phlebotomine sandfly responses to carbon dioxide and human odour in the field. Med Vet Entomol 2001, 15:132-139.

11. Pinto MC, Barbieri K, Silva MCE, Graminha MAS, Casanova C, Andrade AJ, Eiras AE: Octenol as attractant to Nyssomyia neivai (Diptera: Psychodidae: Phlebotominae) in the field. J Med Entomol 2011, 48:39-44.

12. Volf $P$, Volfova $V$ : Establishment and maintenance of sand fly colonies. J Vector Ecol 2011, 36(Suppl 1):S1-S9.

13. Casanova C, Natal D, Santos FAM: Survival, population size, and gonotrophic cycle duration of Nyssomyia neivai (Diptera: Psychodidae) at an endemic area of American cutaneous leishmaniasis in southeastern Brazil. J Med Entomol 2009, 46:42-50. 
14. Córdoba-Lanús E, De Grosso ML, Piñero JE, Valladares B, Salomón OD: Natural infection of Lutzomyia neivai with Leishmania spp. in northwestern Argentina. Acta Trop 2006, 98:1-5.

15. Marcondes CB, Bittencourt IA, Stoco PH, Eger I, Grisard EC, Steindel M: Natural infection of Nyssomyia neivai (Pinto, 1926) (Diptera: Psychodidae, Phlebotominae) by Leishmania (Viannia) spp. in Brazil. Trans R Soc Trop Med Hyg 2009, 103:1093-1097.

16. Fuenzalida AD, Quintana MG, Salomón OD, de Grosso MSL: Hourly activity of Lutzomyia neivai in the endemic zone of cutaneous leishmaniasis in Tucumán, Argentina: preliminary results. Mem Inst Oswaldo Cruz 2011, 106:635-638.

17. Galati EAB: Classificaçâo de Phlebotominae. In Flebotomíneos do Brasil. Edited by Rangel EF, Lainson R. Rio de Janeiro, Brazil: Fiocruz; 2003.

18. Galati EAB: Phylogenetic systematics of Phlebotominae (Diptera, Psychodidae) with emphasis on American groups. Bol Dir Malariol Saneam Amb 1995, 35(suppl. 1):133-142.

19. Young DG, Duran MA: Guide to the Identification and Geographic Distribution of Lutzomyia Sand Flies in Mexico, the West Indies, Central and South America (Diptera: Psychodidae). Mem Am Entomol Inst 1994, 54:1-881.

20. Van Essen PH, Kemme JA, Ritchie SA, Kay BH: Differential responses of Aedes and Culex mosquitoes to octenol or light in combination with carbon dioxide in Queensland, Australia. Med Vet Entomol 1994, 8:63-67.

21. Krockel U, Rose A, Eiras AE, Geier M: New tools for surveillance of adult yellow fever mosquitoes: comparison of trap catches with human landing rates in an urban environment. J Am Mosa Control Assoc 2006, 22:229-238.

22. Fisher RA: Statistical methods for research workers. Edinburgh: Oliver and Boyd; 1970.

23. Cohen J: Statistical power analysis for the behavioral sciences. Hillsdale, N.J.: L. Erlbaum Associates; 1988.

24. Champely S: pwr: Basic functions for power analysis; 2009. Available at http:// CRAN.R-project.org.

25. R Development Core Team: R: A Language and Environment for Statistical Computing. Vienna, Austria: R Foundation for Statistical Computing; 2012

26. Klowden MJ: Endogenous factors regulating mosquito host-seeking behaviour. CIBA Found Symp 1996, 200:212-223. discussion 223-232.

27. Andrade Filho JD, Galati EAB, Falcão AL: Biology of the first generation of a laboratory colony of Nyssomyia intermedia (Lutz \& Neiva, 1912) and Nyssomyia neivai (Pinto, 1926) (Diptera: Psychodidae). Mem Inst Oswaldo Cruz 2004, 99:597-601

28. Matsui K, Sasahara S, Akakabe Y, Kajiwara T: Linoleic acid 10-hydroperoxide as an intermediate during formation of 1-octen-3-ol from linoleic acid in Lentinus decadetes. Biosci Biotechnol Biochem 2003, 67:2280-2282.

29. Xue R-D, Doyle MA, Kline DL: Field evaluation of CDC and Mosquito Magnet (R) $\mathrm{X}$ traps baited with dry ice, $\mathrm{CO}_{2}$ sachet, and octenol against mosquitoes. J Am Mosq Control Assoc 2008, 24:249-252.

30. Hall DR, Beevor PS, Cork A, Nesbitt BF, Vale GA: 1-Octen-3-ol. A Potent Olfactory Stimulant and Attractant for Tsetse Isolated from Cattle Odours. Int J Trop Insect Sci 1984, 5:335-339.

31. Alonso WJ, Schuck-Paim C: The "ghosts" that pester studies on learning in mosquitoes: guidelines to chase them off. Med Vet Entomol 2006, 20:157-165.

32. de Freitas JS, Reinhold-Castro KR, Casanova C, da Silva JP, Previdelli I, Teodoro U: Spatial and/or olfactory memory in sandflies in an endemic area for American cutaneous leishmaniasis, southern Brazil. Rev Soc Bras Med Trop 2009, 42:151-155.

33. Campbell-Lendrum DH, Brandão-Filho SP, Ready PD, Davies CR: Host and/or site loyalty of Lutzomyia whitmani (Diptera: Psychodidae) in Brazil. Med Vet Entomol 1999, 13:209-211.

34. Clements AN: The biology of mosquitoes; Sensory reception and behaviour. Wallingford, UK: CABI Publishing; 1999.

35. Bray DP, Hamilton JGC: Host odor synergizes attraction of virgin female Lutzomyia longipalpis (Diptera: Psychodidae). J Med Entomol 2007 44:779-787.

36. Meireles-Filho AC, da S Rivas GB, Gesto JS, Machado RC, Britto C, de Souza NA, Peixoto AA: The biological clock of an hematophagous insect: Locomotor activity rhythms, circadian expression and downregulation after a blood meal. FEBS Lett 2006, 580:2-8.

37. Acree F Jr, Turner RB, Gouck HK, Beroza M, Smith N: L-Lactic acid: a mosquito attractant isolated from humans. Science 1968, 161:1346-1347.
38. Eiras AE, Jepson P: Host Location by Aedes aegypti (Diptera, Culicidae) - a Wind-Tunnel Study of Chemical Cues. Bull Entomol Res 1991, 81:151-160.

39. Bosch OJ, Geier M, Boeckh J: Contribution of fatty acids to olfactory host finding of female Aedes aegypti. Chem Senses 2000, 25:323-330.

40. Geier M, Bosch OJ, Boeckh J: Ammonia as an attractive component of host odour for the yellow fever mosquito, Aedes aegypti. Chem Senses 1999, 24:647-653.

41. Bernier UR, Kline DL, Allan SA, Barnard DR: Laboratory comparison of Aedes aegypti attraction to human odors and to synthetic human odor compounds and blends. J Am Mosq Control Assoc 2007, 23:288-293.

42. Smallegange RC, Qiu YT, van Loon JJA, Takken W: Synergism between ammonia, lactic acid and carboxylic acids as kairomones in the host-seeking behaviour of the malaria mosquito Anopheles gambiae sensu stricto (Diptera: Culicidae). Chem Senses 2005, 30:145-152.

doi:10.1186/1756-3305-5-210

Cite this article as: Pinto et al:: Attraction of the cutaneous leishmaniasis vector Nyssomyia neivai (Diptera: Psychodidae) to host odour components in a wind tunnel. Parasites \& Vectors 2012 5:210

\section{Submit your next manuscript to BioMed Central and take full advantage of:}

- Convenient online submission

- Thorough peer review

- No space constraints or color figure charges

- Immediate publication on acceptance

- Inclusion in PubMed, CAS, Scopus and Google Scholar

- Research which is freely available for redistribution 